\title{
Effects of Grape Seed Proanthocyanidin Extract on Obesity
}

\author{
Miao Liu ${ }^{a}$ Peng Yun ${ }^{b}$ Ying Hu${ }^{a}$ Jiao Yang ${ }^{a}$ Rim Bahadur Khadkac \\ Xiaochun Peng ${ }^{a}$ \\ ${ }^{a}$ Medical School of Yangtze University, Jingzhou, PR China; ${ }^{b}$ Department of Endocrinology, \\ the Seventh Affiliated Hospital of Sun Yat-sen University, Shenzhen, PR China; 'Yangtze \\ University, Jingzhou, PR China
}

\section{Keywords}

Grape seed proanthocyanidin extract · Obesity $\cdot$ Mechanism

\begin{abstract}
Obesity is a chronic metabolic disease resulting from excessive fat accumulation and/or abnormal distribution caused by multiple factors. As a major component of metabolic syndrome, obesity is closely related to many diseases such as type 2 diabetes mellitus, hyperlipidemia, hypertension, coronary heart disease, stroke and cancer. Hence, the problem of obesity cannot be ignored, and recent studies have shown that grape seed proanthocyanidin extract (GSPE) has an antiobesity effect. This paper systematically reviews the research progress and potential mechanism of GSPE emphasizing on obesity prevention and treatment.

(C) 2020 The Author(s)

Published by S. Karger AG, Basel
\end{abstract}

\section{Introduction}

Obesity is a group of heterogeneous diseases which is associated with many factors, such as genetic factors, bad eating habits, less physical activity, endocrine and metabolic system disorders [1-3], alteration of intestinal flora [4], brown fat dysfunction [5], dysfunction of the nervous system hypothalamus ventrolateral nucleus hunger center and ventromedial nucleus satiety center [6], the disturbance of the biological clock [7] and so on. Complex and diverse causes contribute to the high incidence of obesity: the number of obese people in the world

Miao Liu and Peng Yun contributed equally to this work and should be considered co-first authors.

Dr. Xiaochun Peng

Medical School of Yangtze University

Nanhuan Road 1

Jingzhou City, Hubei Province 434023 (PR China)

pxcwd789@sina.com 
Liu et al.: Effects of GSPE on Obesity

has increased from 105 million in 1975 to 641 million in 2014 [8]. In a nutshell, obesity poses a serious threat to the health of individuals, and more and more evidence shows that obesity is an important risk factor affecting the morbidity and mortality in cardiovascular diseases; also, overweight can increase the mortality of adults suffering from cardiovascular diseases [9]. The body mass index has a linear relationship with the mortality rate of coronary artery disease, stroke and diabetes mellitus [10]. Even modest weight loss can also reduce the risk of these complications [11]. In addition, obesity can lead to gastrointestinal disorders, joint and muscle diseases, respiratory system problems and psychological problems $[12,13]$. In short, obesity is an increasingly serious global public health problem, which seriously affects the daily life of obese people and increases the risk of mortality.

How to prevent and treat obesity has been the focus of attention. Behavioral exercise and drug therapy [14], surgical weight loss [15] and dietary intervention therapy [16] have been the focus of research. But the effect of behavioral exercise on weight loss is slow and obviously unsuitable for obese patients with cardiovascular diseases; every weight loss drug has its own unique risk characteristics, so the doctor needs to fully understand drug contraindications and the differences among obese individuals [17]. More importantly, there is still a lack of long-term experimental studies on whether drug weight loss can cause side effects. Besides, the way of surgical weight loss has been considered controversial for a long time. It can reduce obesity in a short period of time, as $10-30 \%$ of patients who undergo gastric bypass surgery lose weight by 40 or $50 \%$ [18]. However, current evidence shows that the benefits of surgical weight loss are not universal. A considerable proportion of patients will experience weight rebound and recurrence of diabetes [19]. Although exercise, drugs and surgery can achieve effective weight loss, they have limitations, risks and instability, and are not suitable for all obese patients. In this context, a safe and reliable method of reducing obesity with fewer side effects is urgently required by obese people. Compared with behavior, drugs and surgical treatment, dietary strategies for losing weight or improving obesity-related conditions seem to be more anticipated. The use of plant-derived polyphenol flavanone, which has few side effects and widely exists in nature, has aroused interest among many dietary interventions [20-22]. The results of various animal and in vitro experiments show that polyphenols play a beneficial role in the complications of adipocyte-related pathology and dyslipidemia [23].

Grape seed proanthocyanidin extract (GSPE) is a flavonoid polyphenolic compound extracted from grape seeds. It is composed of +catechin, -epicatechin gallate, -epicatechin gallate and -epigallocatechin via C4-C6 or C4-C8 bond links. It exists in the form of monomer and polymer (Fig. 1) [24, 25]. Compared with other plant-derived polyphenols; GSPE has more beneficial health properties, including the ability to modify early cerebrovascular injury caused by hypertension [26], protection of the myocardium from injury [27, 28], prevention and treatment of diabetes and its complications [29], alleviation of exercise fatigue [30] and prevention of obesity and inflammatory reaction [31,32]; it is considered as one of the most effective plant antioxidants, and one of the most effective free radical scavengers [33, 34]. By studying the relationship between GSPE and obesity, we found that GSPE has many activities, such as lowering blood lipid, improving the intestinal flora, regulating the metabolism and so on $[35,36]$. It can effectively prevent obesity in many ways.

\section{Improving Lipid Metabolism}

\section{Correct the Imbalance of Adipokines and Insulin Resistance}

Adipose tissue is an integral part of endocrine organs, and its secreted adipokines are closely related to the occurrence of obesity [37]. Adipose factors participate in regulating the metabolic balance network in vivo through autocrine, paracrine and endocrine forms. When 
Fig. 1. Structure of flavane-3alcohol, procyanidin dimer and procyanidin trimer.
Liu et al.: Effects of GSPE on Obesity

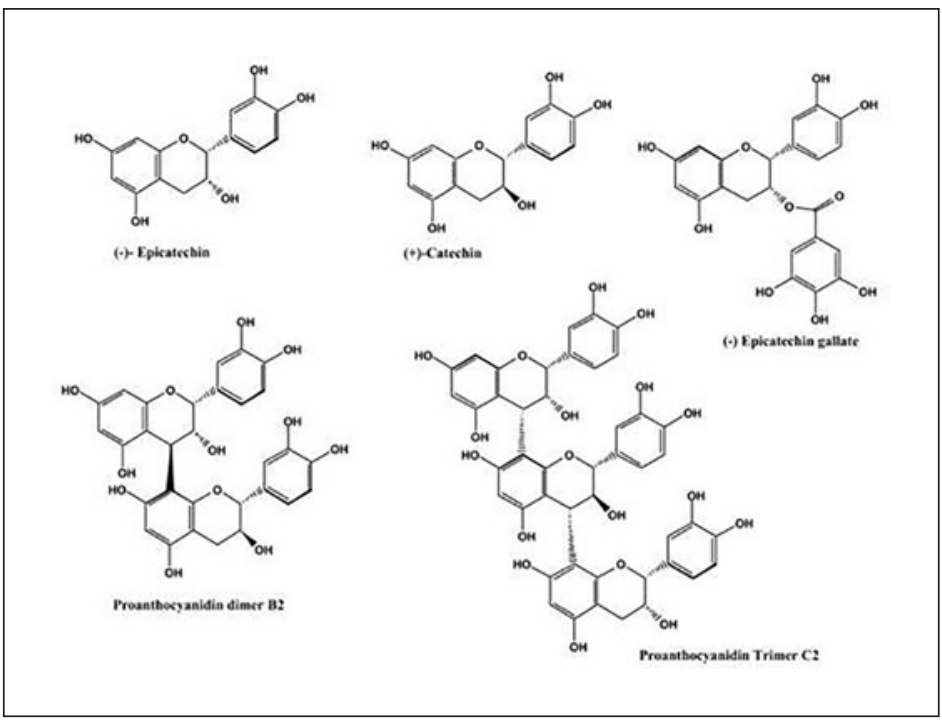

metabolic abnormalities occur, the secretion of adipokines increases and interferes with insulin signaling pathways, increased insulin synthesis and secretion, increased apoptosis of pancreas cells and clearance of insulin by insulin degradation enzyme, resulting in peripheral insulin resistance and disorders of lipid metabolism in vivo [38]. Three groups of hamsters were given a standard diet and a control group was given a high-fat diet/GSPE solution for 12 weeks. Measuring their blood sugar, triglyceride (TG), insulin, leptin and adiponectin. It was found that GSPE prevented the increase in blood sugar, TG, insulin and insulin resistance to a certain extent, and reduced insulinemia and leptin by 16.5 and $45 \%$, cardiac superoxide by $74 \%$, NAD(P)H oxidase by $30 \%$, while adiponectin levels increased by $61 \%$ compared to the high-fat diet control group, suggesting that long-term consumption of GSPE can reduce obesity development and related metabolic pathways by improving adipokine secretion and oxidative stress [39]. Aside from this, chronic supplementation of GSPE can act on insulinsensitive cells, affect the function of pancreatic $\beta$-cells, and prevent the effect of a high-fat diet on pancreatic insulin secretion and lipid accumulation, thus improving insulin resistance. Also, it is worth noting that GSPE intake during lactation could induce insulin resistance and adiponectin resistance phenotypes in obese offspring, which indicates that GSPE had potential as a nutritional supplement during pregnancy [40].

\section{Regulating the Function of White Adipose Tissue and Brown Adipose Tissue}

Adipose tissue is divided into white (WAT) and brown adipose tissues (BAT). WAT stores energy, which is the largest energy reserve in mammals. WAT expands through hypertrophy (increased size of adipocytes) and/or proliferation (increased number of adipocytes). Obesity-related metabolic complications are associated with abnormal WAT expansion [41], because adipocyte hypertrophy is associated with insulin resistance and dyslipidemia. Compared to small adipocytes, hypertrophic adipocytes are more likely to attract inflammatory cells, have more fat-soluble and insulin resistance effects, resulting in metabolic disorders. However, proliferation can prevent metabolic changes [42]. GSPE supplementation can regulate WAT in visceral and subcutaneous tissues, reduce adipocyte hypertrophy and increase adipocyte proliferation, thus improving WAT function.

BAT has an antiobesity effect $[43,44]$ and excision of BAT in animals can lead to an abnormal increase in WAT [45]. Under normal conditions, it consumes energy by self-adapting 
Liu et al.: Effects of GSPE on Obesity

heat production. Obesity was related to the decrease in BAT heat production, and the heat production in obese people was significantly lower than that in lean people [46]. This is because dietary-induced obesity can affect the function of BAT mitochondria, resulting in decreased gene expression of sirtuin protein 1 , nuclear respiratory factor 1 , isocitrate dehydrogenase $3 \gamma$ and $\operatorname{COX} 5 \alpha$, and more importantly, reduced respiratory levels of mitochondria and pyruvate as well as carnitine palmitoyl coenzyme A. But chronic administration of GSPE can increase the oxidase activity of BAT cytochrome $\mathrm{c}$ in obese rats and correct the expression of key genes in BAT mitochondria. Mitochondrial respiratory status with pyruvate and carnitine palmitoyl coenzyme A as substrates in obese rats decreases mitochondrial function, while long-term administration of GSPE can promote mitochondrial respiration, improve mitochondrial function and increase BAT's heat production capacity, thereby increasing energy consumption to prevent weight gain [47].

Some studies have found that some bioactive chemicals can induce WAT browning. GSPE is a flavonoid polyphenol biochemical, which can regulate WAT and BAT. Whether GSPE can induce WAT browning has not been studied yet. However, a new idea has been put forward for us that GSPE may have such a potential mechanism.

\section{Increase the Transcriptional Activity of Bile Acid-Activated FXR and Inhibit Very}

Low-Density Lipoprotein Assembly

Bile acid is an effective low TG preparation, inhibiting the production of hepatic fat and the secretion of TG by activating and binding bile acid receptor (FXR), eliminating lipid protein rich in TG in blood and then lowering the plasma TG level. In the liver, bile acidactivated FXR upregulates the expression of orphan nuclear receptor small isodimer chaperones, thereby inhibiting the expression of transcription factor sterol regulatory element binding protein 1c (SREBP1), resulting in a decrease in fatty acid (FA) synthesis in the liver and an increase in plasma TG catabolism. Therefore, FXR activity plays a key role in the control of TG, cholesterol, bile acid and glucose homeostasis. GSPE can regulate bile acid and lipid metabolism in vivo [48]. By comparing the effects of GSPE on wild type and FXR-null type mice, it was found that GSPE decreased the TG level of wild type mice without affecting the plasma total cholesterol level, but it had no significant effect on the plasma TG level of FXR-null type mice. This indicated that GSPE relied on the FXR pathway to reduce TG and, by enhancing the cdca in CV-1 and Hela cells, to activate the transcriptional activity of FXR $[49,50]$. In addition, GSPE can inhibit very low-density lipoprotein assembly [51, 52], SREBP1 activates the expression of multiple genes involved in FA and TG synthesis, and other components of the lipid metabolism regulation mechanism. Its transcriptional inhibition is related to the synthesis and release of low FA and TG in the liver, leading to hypolipidemia [53]. In conclusion, GSPE can be used as a co-activator of bile acid-dependent FXR activity. GSPE can reduce liver FA synthesis and increase plasma TG catabolism by activating FXR, transient upregulation of orphan nuclear receptor small isodimer chaperone expression [54] and subsequent downregulation of SREBP expression, thereby reducing body fat content.

\section{Inhibiting the c-Jun Aminoterminal Kinase Pathway}

Obesity is associated with an abnormal increase in c-Jun aminoterminal kinase (JNK) activity [55]. JNK is an important component of mitogen-activated protein kinase, also known as stress-activated protein kinase [56]. JNK protein-coding genes include JNK1, JNK2 and JNK3. JNK1 and JNK2 are expressed in all tissues of the body. JNK3 is only expressed in the brain, heart and testis $[57,58]$. In obese mice, increased lipid toxicity pressure activates JNK, and JNK activation leads to insulin resistance [59]. By comparing the effects of GSPE on lipid deposition in mice fed with a normal diet and high-fat diet, it was found that GSPE 
Liu et al.: Effects of GSPE on Obesity

decreased the expression of FA synthase, C/EBP $\alpha$ protein and MPAR $\gamma$ peroxidase receptor mRAN, which are the lipid production-related genes, through inhibiting the JNK pathway effectively reduced fat deposition [60-62] and showed a dose dependency. In a short time, the oral low dose of $25 \mathrm{mg} / \mathrm{kg} /$ day GSPE can reduce the size of WAT in the retroperitoneum, mesentery, epididymis and inguinal region, and prevent fat accumulation [63]. Comparing low, medium and high concentrations of GSPE (100, 200, $400 \mathrm{mg} / \mathrm{kg} /$ day), the low dose group had the best comprehensive lipid-lowering effect [64]. Among 50/100/150 mg/kg/ day GSPE, $150 \mathrm{mg} / \mathrm{kg} /$ day GSPE had the best effect on reducing blood lipid level, body weight, glucose and insulin tolerance in obese mice. The study of dosage-combined administration methods found that the best way to treat obesity metabolic disorder was intermittent administration of $500 \mathrm{mg} / \mathrm{kg}$ at intervals of more than 1 week [65]. A single acute dose of GSPE was satisfactory, increased lipid oxidation of subcutaneous adipose tissue and increased total energy consumption. These combined effects resulted in weight loss. In addition, supplementation of GSPE with aerobic exercise can also reduce obesity in rats fed with a high-fat diet $[66,67]$. Different doses and different ways can reduce fat deposition and obesity, but precise dosage and supplementation methods as well as auxiliary measures are still valuable for research.

\section{Normalizing the Levels of microRNA-33 and microRNA-122}

MicroRNA is a small noncoding RNA with a length of about 22 nucleotides, which horizontally regulates gene expression after transcription. MicroRNAs are involved in almost all biological processes, affecting most metabolic pathways [68]. Obesity leads to overexpression of microRNA-33 and microRNA-122 in the rat liver $[69,70]$ but microRNA-33 and microRNA-122 are the main regulators of liver fat metabolism. In order to evaluate whether chronic intake of GSPE can improve the tolerance to lipid overload, inhibit the expression of hepatic microRNA-33 and microRNA-122, and reduce the increase in TGs in healthy rats after a meal, a dose-response experiment was conducted at 5, 15, 25 or $50 \mathrm{mg} /$ kg GSPE for 3 weeks. The study found that all doses of GSPE inhibited liver expression of miR-33a and miR-122, and reduced plasma and liver lipid levels [71] in a dose-dependent manner.

\section{Interfere with Adipocyte Differentiation}

Fat differentiation is a complex process, which is highly regulated by hormones, cytokines and growth factors. Some molecules such as insulin, insulin-like growth factor-1, glucocorticoid (such as dexamethasone), the cAMP producer isobutyl methylxanthine, and thiazolidinedione have been shown to trigger 3T3-L1 (preadipocyte) to differentiate into adipocytes [72]. GSPE can interfere with the differentiation process of 3T3-L1 adipocytes at the early stage of differentiation. Peroxisome proliferative activation receptor- $\gamma_{2}$ is the main regulator of adipocyte differentiation and plays a central role in the lipolysis of adipocytes by GSPE. It interferes with the development of adipocytes through cell cycle and makes them fully differentiate [73]. In evaluating the effects of GSPE on differentiation, proliferation and lipolysis of porcine adipocytes, it was found that GSPE treatment inhibited preadipocyte differentiation and proliferation, reduced lipid accumulation, decreased expression of peroxisome receptor $\gamma$ and FA binding protein 4 and activity of TG-3-phosphate dehydrogenase by RNA. In mature porcine adipocytes, GSPE reduced lipid content and glycerol phosphate dehydrogenase activity, promoted free FAs and glycerol release; mRNA expression of key lipopolysaccharide transcription factors such as hormone sensitive lipase and fat TG lipase increased [74]. Therefore, it can be concluded that GSPE helps by reducing the formation of new adipocytes to prevent the development of obesity and obesity-related diseases [75, 76]. 
Fig. 2. The mechanism of GSPE on obesity induced by high-fat diet (HFD). Chronic GSPE supplementation significantly changed the composition of the intestinal flora, i.e. the number of thick-walled bacteria (as shown in the gray bacterium) decreased, while the number of bacteria (red bacterium) and bifidobacteria (green bacterium) increased. The change of the microbial community is related to the increase in butyrate production. Butyrate further increased the secretion of GLP-1 in intestinal $\mathrm{L}$ cells and ultimately enhanced metabolic function to prevent obesity.

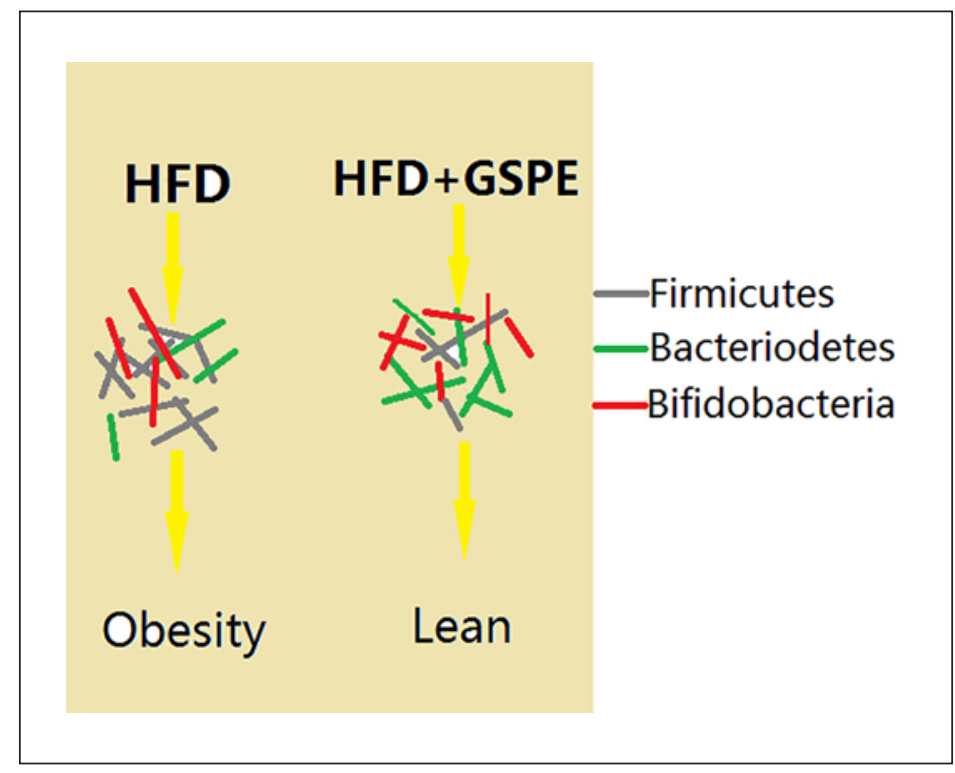

\section{Improving Intestinal Flora}

Regulating the intestinal microflora may be one of the mechanisms of GSPE affecting metabolism. Normal intestinal microflora can promote food metabolism, enhance immunity, participate in mediating fat absorption, transportation, storage and metabolism. Long-term high-fat diet can lead to intestinal microflora disorder, abnormal increase in intestinal permeability, endotoxin, flagellum (the elongated curved filaments of proteins attached to the bodies of certain bacteria), and other harmful substances entering the blood through the intestinal wall and ultimately leading to chronic inflammation and obesity [77]. The intestinal flora is mainly composed of Bacteroides (Gram-negative, spore-free, obligate anaerobic bacilli), Firmicutes (Gram-positive bacteria), and Bifidobacteria (Gram-positive, inactive, rod-shaped, sometimes bifurcated, strictly anaerobic bacteria). Bacteroides participate in the absorption of nutrients and maintain the normal physiological function of the intestinal tract, more Firmicutes than Bacteroides in the intestine can lead to increased energy absorption in the intestinal tract, and excessive energy deposition can lead to obesity. GSPE can modify the intestinal microflora for a short time and increase the number of Bacteroides, decrease the number of Firmicutes and the content of butyric acid in the cecum, and regulate dominant bacteria (Fig. 2) [78]. The 16S rRNA amplifier sequencing technique was used to analyze the intestinal flora structure of a high-fat model and GSPE model. After gavage for 6 weeks, the abundance of Bifidobacterium, Bacteroides and Akkermansia in the GSPE group increased significantly, and the intestinal mucosal degrading bacteria Akkermansia muciniphila increased 70-fold, the intestinal permeability in the GSPE group was significantly lower than that in the high-fat group. GSPE promoted the transition of abnormal intestinal flora structure to normal induced by high-fat diet, repaired intestinal permeability, inhibited chronic inflammation induced by harmful external antigens such as intestinal microorganisms [79, 80], significantly reduced plasma inflammatory factors such as tumor necrosis factor- $\alpha$, interleukin- 6 or monocyte chemoattractant protein-1, improved macrophage infiltration of fat and liver tissue, regulated bacterial content such as that of Clostridium or Prevotella [81], and it was observed that chronic supplementation of GSPE can protect obese rats from dietinduced intestinal changes [82]. 
Fig. 3. The main influence formula of the energy balance framework on appetite control. Green arrows indicate the process of stimulating feeding, while red arrows indicate the process of inhibiting feeding [98]. GSPE increases the secretion of gastrointestinal hormones that inhibit feeding, such as glucagon-like peptide (GLP-1), peptide YY (PYY), cholecystokinin (CCK) and ghrelin.

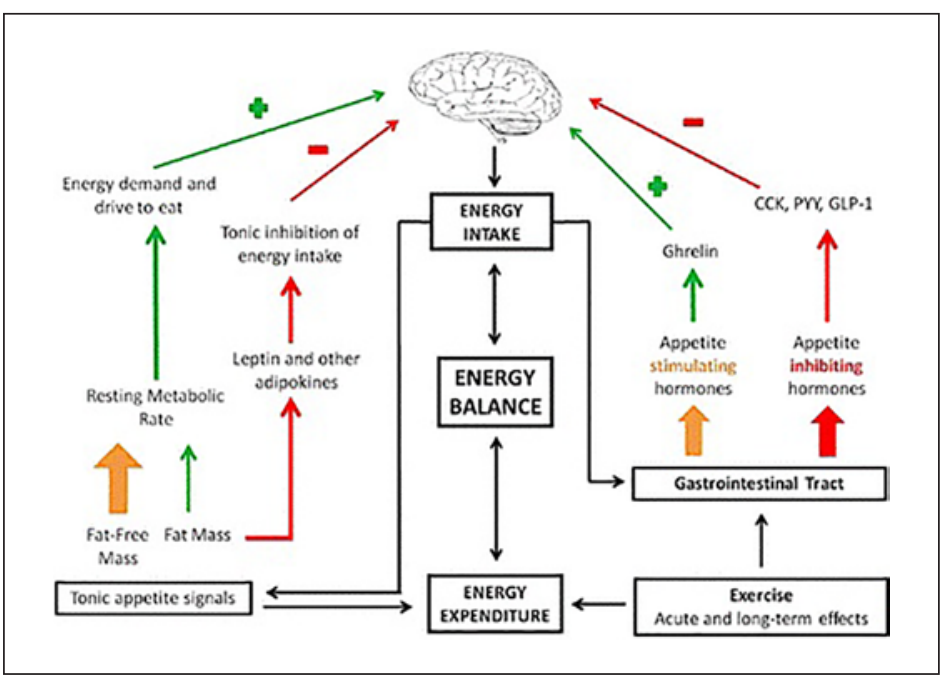

\section{Reduce Food Intake}

Food intake is related to energy balance, which is a dynamic process. There is an interaction between food intake and energy consumption (Fig. 3) [83]. For humans, appetite control is a complex process, and feeding is affected by the hypothalamus and brain centers including the brainstem and hippocampus, as well as the stomach, intestine, liver, thyroid, peripheral adipose tissue, psychological and social behavior [84]. The hypothalamus regulates long-term energy balance and weight by integrating fat hormone signals; the feeding and anorexia neurons in different regions participate in the regulation of food intake by regulating the sensitivity of the posterior brain to short-term satiety hormones [85]; the gastrointestinal endocrine cells produce and secrete satiety hormones, which inhibit hunger, promote satiety and regulate eating behavior through the posterior cerebral circuit. The composition of food nutrients also affects satiety and appetite; foods with high protein content have the strongest satiety and those with high fat content have the weakest satiety [86].

In the gastrointestinal mechanism, GSPE treatment can inhibit digestive enzymes and nutrient digestion and absorption, thereby reducing food intake [87]. However, some studies have shown that GSPE inhibits intestinal $\beta$-glucosidase, improves intestinal amylase, lipase and protease, and improves digestive capacity $[88,89]$. The inconsistency of the experimental results may be due to the small amount of enzymes in the intestinal tract of rats, and individual differences are considerably large. Hence, the result error is caused, and the results need to be verified by further experimental research. In addition, GSPE can reduce gastrointestinal motility. In fasting animals, GSPE inhibits $60 \%$ of intestinal activity and $80 \%$ more strongly after feeding. In the absence of hepatic glucose production on the fasting stomach, the production of intestinal glucose is the necessary condition for maintaining blood glucose homeostasis [90]. Acute GSPE treatment inhibits intestinal gluconeogenesis, downregulates the expression of the glucose transporter Glut-2 and glucokinase in the liver and pancreas [91], reduces the uptake of glucose in the liver and pancreas, resulting in increased levels of portal vein glucose. During fasting, the portal vein glucose level maintained satiety to a certain extent [92]. When glucose is present in the intestine, it stimulates the secretion of intestinal hormones related to satiety in the colon, such as glucagon-like peptide (GLP-1), peptide YY, cholecystokinin and ghrelin.

In the central nervous system, the level of GLP-1 in plasma was elevated by giving $1 \mathrm{~g}$ GSPE/kg to fasting rats [93]. GLP-1 is a peptide hormone coded by the human glucagon gene 
Fig. 4. GSPE regulates the relationship between biological clock and metabolism. GSPE inhibits the interference of the liver and intestine with the peripheral clock and improves the disturbance of the biological clock.

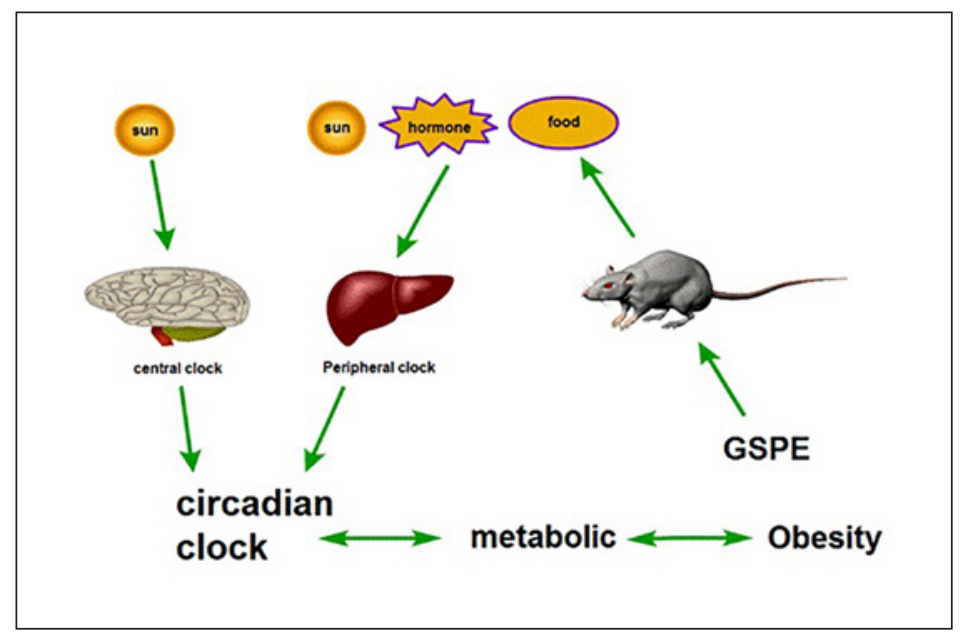

and secreted by intestinal L cells. It can inhibit glucagon secretion, inhibit appetite and feeding, delay gastric emptying and increase satiety [94]. The increase in GLP-1 is a key mediator of GSPE influencing food intake. Sisley et al. [95] have also shown that neuronal GLP-1 receptors mediate the anorexia effect of liraglutide (a persistent GLP-1 agonist). At the same time, GLP-1 activated POMC/CART neurons in the hypothalamus [96], indirectly inhibited neuropeptide $\mathrm{Y} /$ agouti-related peptide neurons through $\beta$-aminobutyric acid transmission, and together produced signals to reduce food intake, which indicated that GSPE affected the hypothalamic center [97], and then controlled food intake. However, the inhibiting effect of GSPE on food intake needs to be exerted at a specific dose without external pressure and calmness. The dosage of $125 \mathrm{mg} / \mathrm{kg}$ GSPE did not reduce food intake. The dosage of $250 \mathrm{mg}$ produced a $15 \%$ inhibiting effect, which increased to $25 \%$ at $500 \mathrm{mg}$, but had a negative effect at $1,000 \mathrm{mg}$. In conclusion, GSPE affects food intake by modifying the GLP-1 signal, inhibiting digestive enzymes and reducing gastrointestinal motility at appropriate doses under nonstress conditions.

\section{Adjusting the Peripheral Clock}

Obesity is related to a disorder of the biological clock. The biological clock is a physiological regulation mechanism of the periodic changes of the biological adaptation to the external environment. It can be divided into the central biological clock and the peripheral biological clock. The central clock is regulated by light, and the peripheral clock is also affected by related hormones and food besides the light regulation (Fig. 4). Obesity is related to fat accumulation in vivo, clock gene expression is related to abdominal fat content, the day-night cycle is related to lipid balance and metabolism in vivo $[99,100]$. Obesity caused by diet can lead to overexpression of some core clock and clock genes [101]. In order to see whether it can regulate the liver and intestine of healthy and obese rats, rats were given different doses of GSPE. It was found that GSPE administration inhibited the interference of clock genes in the liver and intestine [102]. WAT is most sensitive to GSPE [103]. In conclusion, GSPE has a certain role in regulating obesity clock genes. However, it cannot be inferred whether GSPE changes the clock gene first, then the lipid metabolism, or whether the lipid metabolism comes first. Therefore, whether proanthocyanidins can directly regulate the phase, amplitude and/or cycle of peripheral and central clocks remains to be further studied. 
Liu et al.: Effects of GSPE on Obesity

\section{Conclusion and Prospect}

Obesity is a chronic metabolic disease, and there are many mechanisms affecting obesity. GSPE can improve lipid metabolism, reduce fat deposition, improve insulin resistance, increase TG decomposition, improve BAT heat production capacity, improve intestinal flora, reduce food intake, improve the peripheral clock to reduce obesity or prevent further development of obesity. However, most of the studies on the effects of GSPE on obesity remain in animal and cell experiments, and some of the mechanisms of action are less studied. The reliability of the experimental results needs to be further tested. The precise mechanism is not clear. The effect of GSPE on improving lipid metabolism in vivo through different mechanisms has been confirmed. However, whether GSPE can reduce body weight is still controversial. Some experimental results showed that GSPE could reduce the body weight of mice, but there were also some experimental results that showed that the body weight of mice did not change, which may be due to the errors caused by different experimental models, doses and time of use. Future research can be further explored from the following aspects: (1) continue to explore the mechanism between GSPE and obesity, study the relationship between chronic supplementation of GSPE and regulation of the biological clock; (2) rigorously designed largescale randomized trials or meta-analyses of current research and results; (3) clinical exploration of GSPE prevention and treatment of obesity, the optimal dose for obese people.

\section{Acknowledgments}

This work was supported by the Nature Science Foundation of Hubei province (2017CFB786), a medical school Youth Fund of Yangtze University (YXYQ201411) and a Jingzhou Science and Technology Bureau Project (2017-93).

\section{Statement of Ethics}

The authors have no ethical conflicts to disclose.

\section{Disclosure Statement}

No potential conflicts of interest were disclosed.

\section{References}

1 Heymsfield SB, Wadden TA. Mechanisms, pathophysiology, and management of obesity. N Engl J Med. 2017 Jan;376(3):254-66.

2 Kuźbicka K, Rachoń D. Bad eating habits as the main cause of obesity among children. Pediatr Endocrinol Diabetes Metab. 2013;19(3):106-10.

3 Day FR, Loos RJ. Developments in obesity genetics in the era of genome-wide association studies. J Nutrigenet Nutrigenomics. 2011;4(4):222-38.

4 Casanova-Martí À, Serrano J, Portune KJ, Sanz Y, Blay MT, Terra X, et al. Grape seed proanthocyanidins influence gut microbiota and enteroendocrine secretions in female rats. Food Funct. 2018 Mar;9(3):1672-82.

5 Wang GX, Zhao XY, Lin JD. The brown fat secretome: metabolic functions beyond thermogenesis. Trends Endocrinol Metab. 2015 May;26(5):231-7.

6 Timper K, Brüning JC. Hypothalamic circuits regulating appetite and energy homeostasis: pathways to obesity. Dis Model Mech. 2017 Jun;10(6):679-89.

7 Albrecht U. The circadian clock, metabolism and obesity. Obes Rev. 2017 Feb;18 Suppl 1:25-33. 
Liu et al.: Effects of GSPE on Obesity

8 NCD Risk Factor Collaboration (NCD-RisC). Trends in adult body-mass index in 200 countries from 1975 to 2014: a pooled analysis of 1698 population-based measurement studies with $19 \cdot 2$ million participants. Lancet. 2016 Apr;387(10026):1377-96.

9 Martin KA, Mani MV, Mani A. New targets to treat obesity and the metabolic syndrome. Eur J Pharmacol. 2015 Sep;763 Pt A:64-74.

10 Whitlock G, Lewington S, Sherliker P, Clarke R, Emberson J, Halsey J, et al.; Prospective Studies Collaboration. Body-mass index and cause-specific mortality in 900000 adults: collaborative analyses of 57 prospective studies. Lancet. 2009 Mar;373(9669):1083-96.

11 Cefalu WT, Bray GA, Home PD, Garvey WT, Klein S, Pi-Sunyer FX, et al. Advances in the science, treatment, and prevention of the disease of obesity: reflections from a diabetes care editors' expert forum. Diabetes Care. 2015 Aug;38(8):1567-82.

12 Fruh SM. Obesity: risk factors, complications, and strategies for sustainable long-term weight management. J Am Assoc Nurse Pract. 2017 Oct;29 S1:S3-14.

13 Avila C, Holloway AC, Hahn MK, Morrison KM, Restivo M, Anglin R, et al. An overview of links between obesity and mental health. Curr Obes Rep. 2015 Sep;4(3):303-10.

14 LeBlanc ES, Patnode CD, Webber EM, Redmond N, Rushkin M, O'Connor EA. Behavioral and pharmacotherapy weight loss interventions to prevent Obesity-Related morbidity and mortality in adults: updated evidence report and systematic review for the US preventive services task force. JAMA. 2018 Sep;320(11):1172-91.

15 Coen PM, Carnero EA, Goodpaster BH. Exercise and bariatric surgery: an effective therapeutic strategy. Exerc Sport Sci Rev. 2018 Oct;46(4):262-70.

16 Mandecka A, Regulska-Ilow B. Dietary interventions in the treatment of metabolic syndrome as a cardiovascular disease risk-inducing factor. A review. Rocz Panstw Zakl Hig. 2018;69(3):227-33.

17 Fujioka K. Safety and tolerability of medications approved for chronic weight management. Obesity (Silver Spring). 2015 Apr;23 Suppl 1:S7-11.

18 Campos GM, Rabl C, Mulligan K, Posselt A, Rogers SJ, Westphalen AC, et al. Factors associated with weight loss after gastric bypass. Arch Surg. 2008 Sep;143(9):877-83.

19 Brethauer SA, Aminian A, Romero-Talamas H, Batayyah E, Mackey J, Kennedy L, Kashyap SR, Kirwan JP, Rogula T, Kroh M, Chand B, Schauer PR. Can diabetes be surgically cured? Long-term metabolic effects of bariatric surgery in obese patients with type 2 diabetes mellitus. Ann Surg 2013;258:628-37.

20 Shimada T, Tokuhara D, Tsubata M, Kamiya T, Kamiya-Sameshima M, Nagamine R, et al. Flavangenol (pine bark extract) and its major component procyanidin B1 enhance fatty acid oxidation in fat-loaded models. Eur J Pharmacol. 2012 Feb;677(1-3):147-53.

21 Dorenkott MR, Griffin LE, Goodrich KM, Thompson-Witrick KA, Fundaro G, Ye L, et al. Oligomeric cocoa procyanidins possess enhanced bioactivity compared to monomeric and polymeric cocoa procyanidins for preventing the development of obesity, insulin resistance, and impaired glucose tolerance during high-fat feeding. J Agric Food Chem. 2014 Mar;62(10):2216-27.

22 Dallas C, Gerbi A, Elbez Y, Caillard P, Zamaria N, Cloarec M. Clinical study to assess the efficacy and safety of a citrus polyphenolic extract of red orange, grapefruit, and orange (Sinetrol-XPur) on weight management and metabolic parameters in healthy overweight individuals. Phytother Res. 2014 Feb;28(2):212-8.

23 Rodriguez-Perez C, Segura-Carretero A, Del MC. Phenolic compounds as natural and multifunctional antiobesity agents: a review. Crit Rev Food Sci Nutr. 2019;59(8):1212-29.

24 Monagas M, Quintanilla-López JE, Gómez-Cordovés C, Bartolomé B, Lebrón-Aguilar R. MALDI-TOF MS analysis of plant proanthocyanidins. J Pharm Biomed Anal. 2010 Jan;51(2):358-72.

25 Prasain JK, Peng N, Dai Y, Moore R, Arabshahi A, Wilson L, et al. Liquid chromatography tandem mass spectrometry identification of proanthocyanidins in rat plasma after oral administration of grape seed extract. Phytomedicine. 2009 Mar;16(2-3):233-43.

26 Hao JP, Shi H, Zhang J, Zhang CM, Feng YM, Qie LY, et al. Role of GSPE in improving early cerebral vascular damage by inhibition of Profilin-1 expression in a ouabain-induced hypertension model. Eur Rev Med Pharmacol Sci. 2018 Oct;22(20):6999-7012.

27 Yang D, Li S, Gao L, Lv Z, Bing Q, Lv Q, et al. Dietary grape seed procyanidin extract protects against leadinduced heart injury in rats involving endoplasmic reticulum stress inhibition and AKT activation. J Nutr Biochem. 2018 Dec;62:43-9.

28 Pons Z, Margalef M, Bravo FI, Arola-Arnal A, Muguerza B. Chronic administration of grape-seed polyphenols attenuates the development of hypertension and improves other cardiometabolic risk factors associated with the metabolic syndrome in cafeteria diet-fed rats. Br J Nutr. 2017 Jan;117(2):200-8.

29 Gao Z, Liu G, Hu Z, Shi W, Chen B, Zou P, et al. Grape seed proanthocyanidins protect against streptozotocin-induced diabetic nephropathy by attenuating endoplasmic reticulum stress-induced apoptosis. Mol Med Rep. 2018 Aug;18(2):1447-54.

30 Xianchu L, Ming L, Xiangbin L, Lan Z. Grape seed proanthocyanidin extract supplementation affects exhaustive exercise-induced fatigue in mice. Food Nutr Res. 2018 Jun;62(0):62.

31 Décordé K, Teissèdre PL, Sutra T, Ventura E, Cristol JP, Rouanet JM. Chardonnay grape seed procyanidin extract supplementation prevents high-fat diet-induced obesity in hamsters by improving adipokine imbalance and oxidative stress markers. Mol Nutr Food Res. 2009 May;53(5):659-66.

32 Chacón MR, Ceperuelo-Mallafré V, Maymó-Masip E, Mateo-Sanz JM, Arola L, Guitiérrez C, et al. Grape-seed procyanidins modulate inflammation on human differentiated adipocytes in vitro. Cytokine. 2009 Aug;47(2):137-42. 
Liu et al.: Effects of GSPE on Obesity

Sherif AA, Abdelhalim SZ, Salim EI. Immunohistochemical and biochemical alterations following administration of proanthocyanidin extract in rats hepatocellular carcinoma. Biomed Pharmacother. 2017 Sep;93: 1310-9.

34 Bagchi D, Bagchi M, Stohs SJ, Das DK, Ray SD, Kuszynski CA, et al. Free radicals and grape seed proanthocyanidin extract: importance in human health and disease prevention. Toxicology. 2000 Aug;148(2-3):187-97. Pinent M, Bladé C, Salvadó MJ, Blay M, Pujadas G, Fernández-Larrea J, et al. Procyanidin effects on adipocyterelated pathologies. Crit Rev Food Sci Nutr. 2006;46(7):543-50.

36 Jhun JY, Moon SJ, Yoon BY, Byun JK, Kim EK, Yang EJ, et al. Grape seed proanthocyanidin extract-mediated regulation of STAT3 proteins contributes to Treg differentiation and attenuates inflammation in a murine model of obesity-associated arthritis. PLoS One. 2013 Nov;8(11):e78843.

37 Terra X, Montagut G, Bustos M, Llopiz N, Ardèvol A, Bladé C, et al. Grape-seed procyanidins prevent low-grade inflammation by modulating cytokine expression in rats fed a high-fat diet. J Nutr Biochem. 2009 Mar;20(3): $210-8$.

38 Ouchi N, Parker JL, Lugus JJ, Walsh K. Adipokines in inflammation and metabolic disease. Nat Rev Immunol. 2011 Feb;11(2):85-97.

39 Junsong X, Ying W, Xuelin S, Hua W, Jingmin D, Yanping C. Effects of proanthocyanidins on oxidative stress in nutritional obesity rats. Shipin Kexue. 2014;35:183-6.

40 Caimari A, Mariné-Casadó R, Boqué N, Crescenti A, Arola L, Del Bas JM. Maternal intake of grape seed procyanidins during lactation induces insulin resistance and an adiponectin resistance-like phenotype in rat offspring. Sci Rep. 2017 Oct; 7(1):12573.

41 Pascual-Serrano A, Bladé C, Suárez M, Arola-Arnal A. Grape seed proanthocyanidins improve white adipose tissue expansion during Diet-Induced obesity development in rats. Int J Mol Sci. 2018 Sep;19(9):2632.

42 Pascual-Serrano A, Arola-Arnal A, Suárez-García S, Bravo FI, Suárez M, Arola L, et al. Grape seed proanthocyanidin supplementation reduces adipocyte size and increases adipocyte number in obese rats. Int J Obes. 2017 Aug;41(8):1246-55.

43 Shankar K, Kumar D, Gupta S, Varshney S, Rajan S, Srivastava A, et al. Role of brown adipose tissue in modulating adipose tissue inflammation and insulin resistance in high-fat diet fed mice. Eur J Pharmacol. 2019 Jul; 854:354-64.

44 Scheele C, Nielsen S. Metabolic regulation and the anti-obesity perspectives of human brown fat. Redox Biol. 2017 Aug; 12:770-5.

45 Pajuelo D, Quesada H, Díaz S, Fernández-Iglesias A, Arola-Arnal A, Bladé C, et al. Chronic dietary supplementation of proanthocyanidins corrects the mitochondrial dysfunction of brown adipose tissue caused by dietinduced obesity in Wistar rats. Br J Nutr. 2012 Jan;107(2):170-8.

46 van Marken Lichtenbelt WD, Vanhommerig JW, Smulders NM, Drossaerts JM, Kemerink GJ, Bouvy ND, et al. Cold-activated brown adipose tissue in healthy men. N Engl J Med. 2009 Apr;360(15):1500-8.

47 Pajuelo D, Díaz S, Quesada H, Fernández-Iglesias A, Mulero M, Arola-Arnal A, et al. Acute administration of grape seed proanthocyanidin extract modulates energetic metabolism in skeletal muscle and BAT mitochondria. J Agric Food Chem. 2011 Apr;59(8):4279-87.

48 Downing LE, Edgar D, Ellison PA, Ricketts ML. Mechanistic insight into nuclear receptor-mediated regulation of bile acid metabolism and lipid homeostasis by grape seed procyanidin extract (GSPE). Cell Biochem Funct. 2017 Jan;35(1):12-32.

49 Del Bas JM, Ricketts ML, Vaqué M, Sala E, Quesada H, Ardevol A, et al. Dietary procyanidins enhance transcriptional activity of bile acid-activated FXR in vitro and reduce triglyceridemia in vivo in a FXR-dependent manner. Mol Nutr Food Res. 2009 Jul;53(7):805-14.

50 Heidker RM, Caiozzi GC, Ricketts ML. Dietary procyanidins selectively modulate intestinal farnesoid X receptor-regulated gene expression to alter enterohepatic bile acid recirculation: elucidation of a novel mechanism to reduce triglyceridemia. Mol Nutr Food Res. 2016 Apr;60(4):727-36.

51 Quesada H, Díaz S, Pajuelo D, Fernández-Iglesias A, Garcia-Vallvé S, Pujadas G, et al. The lipid-lowering effect of dietary proanthocyanidins in rats involves both chylomicron-rich and VLDL-rich fractions. Br J Nutr. 2012 Jul;108(2):208-17.

52 Baiges I, Palmfeldt J, Bladé C, Gregersen N, Arola L. Lipogenesis is decreased by grape seed proanthocyanidins according to liver proteomics of rats fed a high fat diet. Mol Cell Proteomics. 2010 Jul;9(7):1499-513.

53 Quesada H, del Bas JM, Pajuelo D, Díaz S, Fernandez-Larrea J, Pinent M, et al. Grape seed proanthocyanidins correct dyslipidemia associated with a high-fat diet in rats and repress genes controlling lipogenesis and VLDL assembling in liver. Int J Obes. 2009 Sep;33(9):1007-12.

54 Inoue J, Tanaka M, Nanmoku M, Yashiro T, Sato R. Stabilization of small heterodimer partner mRNA by grape seed procyanidins extract in cultured hepatocytes. Mol Nutr Food Res. 2011 Jul;55(7):1052-8.

55 Solinas G, Becattini B. JNK at the crossroad of obesity, insulin resistance, and cell stress response. Mol Metab. 2016 Dec;6(2):174-84.

56 Zeke A, Misheva M, Reményi A, Bogoyevitch MA. JNK Signaling: Regulation and Functions Based on Complex Protein-Protein Partnerships. Microbiol Mol Biol Rev. 2016 Jul;80(3):793-835.

57 Crescenti A, del Bas JM, Arola-Arnal A, Oms-Oliu G, Arola L, Caimari A. Grape seed procyanidins administered at physiological doses to rats during pregnancy and lactation promote lipid oxidation and up-regulate AMPK in the muscle of male offspring in adulthood. J Nutr Biochem. 2015 Sep;26(9):912-20. 
Liu et al.: Effects of GSPE on Obesity

58 Sato M, Bagchi D, Tosaki A, Das DK. Grape seed proanthocyanidin reduces cardiomyocyte apoptosis by inhibiting ischemia/reperfusion-induced activation of JNK-1 and C-JUN. Free Radic Biol Med. 2001 Sep;31(6):72937.

59 Yazıcı D, Sezer H. Insulin resistance, obesity and lipotoxicity. Adv Exp Med Biol. 2017;960:277-304.

60 Bagchi D, Sen CK, Ray SD, Das DK, Bagchi M, Preuss HG, et al. Molecular mechanisms of cardioprotection by a novel grape seed proanthocyanidin extract. Mutat Res. 2003 Feb-Mar;523-524:87-97.

61 Jia Z, Song Z, Zhao Y, Wang X, Liu P. Grape seed proanthocyanidin extract protects human lens epithelial cells from oxidative stress via reducing NF-кB and MAPK protein expression. Mol Vis. 2011 Jan;17:210-7.

62 Kim H, Kim JY, Song HS, Park KU, Mun KC, Ha E. Grape seed proanthocyanidin extract inhibits interleukin17-induced interleukin-6 production via MAPK pathway in human pulmonary epithelial cells. Naunyn Schmiedebergs Arch Pharmacol. 2011 Jun;383(6):555-62.

63 Caimari A, del Bas JM, Crescenti A, Arola L. Low doses of grape seed procyanidins reduce adiposity and improve the plasma lipid profile in hamsters. Int J Obes. 2013 Apr;37(4):576-83.

64 Serrano J, Casanova-Martí À, Gual A, Pérez-Vendrell AM, Blay MT, Terra X, et al. A specific dose of grape seedderived proanthocyanidins to inhibit body weight gain limits food intake and increases energy expenditure in rats. Eur J Nutr. 2017 Jun;56(4):1629-36.

65 Ginés I, Gil-Cardoso K, Serrano J, Casanova-Martí À, Blay M, Pinent M, et al. Effects of an intermittent GrapeSeed proanthocyanidin (GSPE) treatment on a cafeteria diet obesogenic challenge in rats. Nutrients. 2018 Mar; $10(3): 315$.

66 Abhijit S, Tripathi SJ, Bhagya V, Shankaranarayana Rao BS, Subramanyam MV, Asha Devi S. Antioxidant action of grape seed polyphenols and aerobic exercise in improving neuronal number in the hippocampus is associated with decrease in lipid peroxidation and hydrogen peroxide in adult and middle-aged rats. Exp Gerontol. 2018 Jan;101:101-12.

67 Hongli ZH, Yaning ZH, Zhengwei H, Yan L. Effects of resistance exercise combined with oral grape seed proanthocyanidins on body shape, serum leptin level and sleep of adolescent OSAHS patients. J Nurs Educ. 2017;32: 1175-7.

68 Blade C, Baselga-Escudero L, Arola-Arnal A. microRNAs as new targets of dietary polyphenols. Curr Pharm Biotechnol. 2014;15(4):343-51.

69 Baselga-Escudero L, Pascual-Serrano A, Ribas-Latre A, Casanova E, Salvadó MJ, Arola L, et al. Long-term supplementation with a low dose of proanthocyanidins normalized liver miR-33a and miR-122 levels in high-fat diet-induced obese rats. Nutr Res. 2015 Apr;35(4):337-45.

70 Baselga-Escudero L, Blade C, Ribas-Latre A, Casanova E, Salvadó MJ, Arola L, et al. Chronic supplementation of proanthocyanidins reduces postprandial lipemia and liver miR-33a and miR-122 levels in a dose-dependent manner in healthy rats. J Nutr Biochem. 2014 Feb;25(2):151-6.

71 Castell-Auví A, Cedó L, Movassat J, Portha B, Sánchez-Cabo F, Pallarès V, et al. Procyanidins modulate microRNA expression in pancreatic islets. J Agric Food Chem. 2013 Jan;61(2):355-63.

72 Takamura T, Nohara E, Nagai Y, Kobayashi K. Stage-specific effects of a thiazolidinedione on proliferation, differentiation and PPARgamma mRNA expression in 3T3-L1 adipocytes. Eur J Pharmacol. 2001 Jun;422(1-3): 23-9.

73 Pinent M, Bladé MC, Salvadó MJ, Arola L, Hackl H, Quackenbush J, et al. Grape-seed derived procyanidins interfere with adipogenesis of 3T3-L1 cells at the onset of differentiation. Int J Obes. 2005 Aug;29(8):934-41.

74 Wei S, Zheng Y, Zhang M, Zheng H, Yan P. Grape seed procyanidin extract inhibits adipogenesis and stimulates lipolysis of porcine adipocytes in vitro. J Anim Sci. 2018 Jun;96(7):2753-62.

75 Zhai O, Zhong N, Gao HQ, Li BY, Jiang B. Grape seed proanthocyanidins extracts promote apolipoprotein A-I mRNA expression in HepG2 cells under experimental sugar and high-sugar conditions. Eur Rev Med Pharmacol Sci. 2012 Mar;16(3):299-304.

76 Guerrero L, Margalef M, Pons Z, Quiñones M, Arola L, Arola-Arnal A, et al. Serum metabolites of proanthocyanidin-administered rats decrease lipid synthesis in HepG2 cells. J Nutr Biochem. 2013 Dec;24(12):2092-9.

77 Nagpal R, Newman TM, Wang S, Jain S, Lovato JF, Yadav H. Obesity-linked gut microbiome dysbiosis associated with derangements in gut permeability and intestinal cellular homeostasis independent of diet. J Diabetes Res. 2018 Sep;2018:3462092.

78 Xuelin S, Yamei L, Junsong X, Hua W, Yanping C. Effects of grape seed proanthocyanidins on intestinal flora in rats with nutritional obesity. J Food Sci Technol. 2015;33:39-46.

79 Gil-Cardoso K, Ginés I, Pinent M, Ardévol A, Blay M, Terra X. The co-administration of proanthocyanidins and an obesogenic diet prevents the increase in intestinal permeability and metabolic endotoxemia derived to the diet. J Nutr Biochem. 2018 Dec;62:35-42.

80 Gil-Cardoso K, Comitato R, Ginés I, Ardévol A, Pinent M, Virgili F, et al. Protective effect of proanthocyanidins in a rat model of mild intestinal inflammation and impaired intestinal permeability induced by LPS. Mol Nutr Food Res. 2019 Apr;63(8):e1800720.

81 Liu W, Zhao S, Wang J, Shi J, Sun Y, Wang W, et al. Grape seed proanthocyanidin extract ameliorates inflammation and adiposity by modulating gut microbiota in high-fat diet mice. Mol Nutr Food Res. 2017 Sep;61(9): 61.

82 Gil-Cardoso K, Ginés I, Pinent M, Ardévol A, Arola L, Blay M, et al. Chronic supplementation with dietary proanthocyanidins protects from diet-induced intestinal alterations in obese rats. Mol Nutr Food Res. 2017 Aug; 61(8):61. 
Liu et al.: Effects of GSPE on Obesity

83 Hopkins M, Blundell JE. Energy balance, body composition, sedentariness and appetite regulation: pathways to obesity. Clin Sci (Lond). 2016 Sep;130(18):1615-28.

84 Panickar KS. Effects of dietary polyphenols on neuroregulatory factors and pathways that mediate food intake and energy regulation in obesity. Mol Nutr Food Res. 2013 Jan;57(1):34-47.

85 Rui L. Brain regulation of energy balance and body weight. Rev Endocr Metab Disord. 2013 Dec;14(4):387407.

86 Psichas A, Reimann F, Gribble FM. Gut chemosensing mechanisms. J Clin Invest. 2015 Mar;125(3):908-17.

87 Yilmazer-Musa M, Griffith AM, Michels AJ, Schneider E, Frei B. Grape seed and tea extracts and catechin 3 -gallates are potent inhibitors of $\alpha$-amylase and $\alpha$-glucosidase activity. J Agric Food Chem. 2012 Sep;60(36): 8924-9.

88 Gonçalves R, Mateus N, de Freitas V. Study of the interaction of pancreatic lipase with procyanidins by optical and enzymatic methods. J Agric Food Chem. 2010 Nov;58(22):11901-6.

89 Yamei L, Shuo F, Junsong X, Yanping C. Effects of proanthocyanidins on intestinal digestive enzymes in nutritional obesity rats. Food Industry Technol. 2016;37:364-7.

90 Penhoat A, Fayard L, Stefanutti A, Mithieux G, Rajas F. Intestinal gluconeogenesis is crucial to maintain a physiological fasting glycemia in the absence of hepatic glucose production in mice. Metabolism. 2014 Jan;63(1): 104-11.

91 Castell-Auví A, Cedó L, Pallarès V, Blay MT, Pinent M, Motilva MJ, et al. Procyanidins modify insulinemia by affecting insulin production and degradation. J Nutr Biochem. 2012 Dec;23(12):1565-72.

92 Casanova-Martí À, Serrano J, Blay MT, Terra X, Ardévol A, Pinent M. Acute selective bioactivity of grape seed proanthocyanidins on enteroendocrine secretions in the gastrointestinal tract. Food Nutr Res. 2017 Jun; 61(1):1321347.

93 Serrano J, Casanova-Martí À, Blay M, Terra X, Ardévol A, Pinent M. Defining conditions for optimal inhibition of food intake in rats by a Grape-Seed derived proanthocyanidin extract. Nutrients. 2016 0ct;8(10):8.

94 Hellström PM, Näslund E, Edholm T, Schmidt PT, Kristensen J, Theodorsson E, et al. GLP-1 suppresses gastrointestinal motility and inhibits the migrating motor complex in healthy subjects and patients with irritable bowel syndrome. Neurogastroenterol Motil. 2008 Jun;20(6):649-59.

95 Sisley S, Gutierrez-Aguilar R, Scott M, D’Alessio DA, Sandoval DA, Seeley RJ. Neuronal GLP1R mediates liraglutide's anorectic but not glucose-lowering effect. J Clin Invest. 2014 Jun;124(6):2456-63.

96 Ibars M, Ardid-Ruiz A, Suárez M, Muguerza B, Bladé C, Aragonès G. Proanthocyanidins potentiate hypothalamic leptin/STAT3 signalling and Pomc gene expression in rats with diet-induced obesity. Int J Obes. 2017 Jan;41(1):129-36.

97 Baggio LL, Drucker DJ. Glucagon-like peptide-1 receptors in the brain: controlling food intake and body weight. J Clin Invest. 2014 Oct;124(10):4223-6.

98 Blundell JE, Gibbons C, Caudwell P, Finlayson G, Hopkins M. Appetite control and energy balance: impact of exercise. Obes Rev. 2015 Feb;16 Suppl 1:67-76.

99 Hernández-García J, Navas-Carrillo D, Orenes-Piñero E. Alterations of circadian rhythms and their impact on obesity, metabolic syndrome and cardiovascular diseases. Crit Rev Food Sci Nutr. 2019 Jan;1:1-10.

100 Meyhöfer S, Wilms B, Oster H, Schmid SM. [Importance of sleep and circadian rhythm for energy metabolism]. Internist (Berl). 2019 Feb;60(2):122-7.

101 Rácz B, Dušková M, Stárka L, Hainer V, Kunešová M. Links between the circadian rhythm, obesity and the microbiome. Physiol Res. 2018 Nov;67 Suppl 3:S409-20.

102 Ribas-Latre A, Baselga-Escudero L, Casanova E, Arola-Arnal A, Salvadó MJ, Bladé C, et al. Dietary proanthocyanidins modulate BMAL1 acetylation, Nampt expression and NAD levels in rat liver. Sci Rep. 2015 Jun;5(1): 10954.

103 Ribas-Latre A, Baselga-Escudero L, Casanova E, Arola-Arnal A, Salvadó MJ, Arola L, et al. Chronic consumption of dietary proanthocyanidins modulates peripheral clocks in healthy and obese rats. J Nutr Biochem. 2015 Feb;26(2):112-9. 